\title{
Research on Introducing Flipped Classroom into the Public Physical Education in Colleges and Universities
}

\author{
Xizhe Bao \\ Guangzhou Medical University, China
}

Keywords: Flipped classrooms, colleges and universities, public physical education.

\begin{abstract}
In today's society where information technology continues to develop and progress, China's education system is also constantly reforming and innovating. In the field of education and teaching, the application of information technology is more and more extensive, and the information-based teaching model will inevitably become the development trend of education. Flipped classroom is a new teaching method in recent years. The teaching model based on information-based teaching has been applied in the teaching of many subjects, but it is not widely used in physical education. Therefore, flipped classroom is introduced into the public physical education for analysis and research.
\end{abstract}

\section{Introduction}

In today's society, technology has become the primary productive force. Therefore, the use of technology in any field is necessary. Schools that are the cradle of technology should enjoy the convenience of technology. Especially after the introduction of multimedia teaching in schools, more and more advanced classroom models have become the mainstream classrooms currently recommended by the school. In the new classroom, MOOC and flip classroom are the most common and effective classrooms. But these new classes are focused on some high-tech, high-tech courses, especially in the field of mathematics and physics. Courses in these areas seem to be very well developed, but some new experimental classes will still appear on these courses [1]. Although the physical education curriculum was established earlier, it has not been valued. Don't say that the new form of classroom is education reform, and it has hardly happened. Take this old traditional form of physical education. The teacher also uses the interest-based approach in the training of the students, so that the classroom is almost playful. Moreover, the examinations of physical education courses are not strict enough, almost participation can be passed, and the teachers will score according to the usual performance, and the relationship with technology is not great. In some professional sports colleges, although the teachers are stricter, they can cultivate students' sports ability, but this ability is achieved by simple hard training [1]. The daily task of the course is heavy, and it has long caused a certain burden on the students' psychology and physiology. Therefore, it is especially important to build a new flip classroom in the physical education curriculum. In particular, flipping the classroom allows students to better grasp the theoretical basis of sports, and in the classroom, they can play better. At the same time, the physical education classroom is generally accompanied by a certain degree of risk, and better mastery of theoretical knowledge can better prevent the occurrence of injuries, and gain more in one fell swoop.

\section{The status quo and problems of physical education in colleges and universities}

At present, although China has made some achievements in the sports industry, there are still some problems in physical education. China's physical education is mainly practice-oriented, and it does not pay much attention to the cultivation of spirit and emotion. The problems that teachers should consider are mainly teaching content, teaching methods and students. The learning effect ignores the students' learning emotions and attitudes [1]. Therefore, the classroom mode is still instilled, and students can acquire certain practical ability, but it is not conducive to cultivating students' enthusiasm for sports learning, and it is not conducive to students' lifelong physical exercise 
consciousness. to cultivate. To improve the efficiency of physical education, it is necessary to understand the inner feelings of students through various aspects in order to achieve the teaching objectives.

The traditional mode of physical education in China is the teacher as the main body, the students as the object, the teaching objectives, teaching tasks; teaching content, teaching methods, etc. are all selected by the teachers according to their own considerations and preferences. The classroom is the performance stage of the physical education teachers themselves [2]. In fact, each Student's understanding of the contents of the teachers is not the same, and the actions may not be in place. This requires teachers to give pointers one by one. Students who perform well have no breakthroughs. Students with poor performance will become worse and worse. Students only have to obey themselves. Independence has seriously affected the development goals of physical education.

Physical education has a certain degree of risk. Physical education curriculum must regard health as the primary consideration. It is the foundation of theoretical knowledge and technical fitness. It is a long-term teaching strategy, and the individual ability and training results for students [2]. Not fully paid attention to, although the current physical education curriculum has also carried out a variety of teaching models, but too many ideas have not made physical education more improved, but the teaching process and goals are more chaotic, and finally the emergence of theoretical knowledge, student personalization ability Insufficient results are cultivated; the students' teaching experience process is more important, but the results of the students' teaching experience are too neglect; the students' health is more important, while the professional skills are more neglected.

The traditional assessment is based on theory and skills. The evaluation is only based on the high scores of the scores. There is not much emphasis on whether students have progressed. Whether there is any effort in the learning process, the main purpose of the evaluation should be to promote students' learning. Not just scores, it affects students' interest in learning [3].

\section{Flip the class introduction}

\subsection{Flipping the origins of the class.}

The "Flip Classroom" originated from the Bangladeshi American Selman Khan. He used his recorded instructional videos to receive unexpected results in the course of tutoring mathematics for prostitutes and nephews. In November 2006, his first teaching video was published on the website and attracted a lot of attention. In 2007, Khan established a non-profit "Khan Academy" website, video tutorials in the form of individual cases. Although the form and structure are very rough, it has fully reflected the rational application of the teaching video. The students are in an active position in the students' preparation, review and practice guidance [3].

In 2007, two high school teachers, Jonathan Berman and Aaron Sams, produced some videos about the content of the lectures in order to solve the students' remedial problems, so that students can learn independently at home and complete the class [4]. After a period of practice, the two teachers found that this method of learning is very suitable for students' learning characteristics and has been widely welcomed by students. In addition, teachers can save classroom time through this teaching method, which can help students solve more classroom problems. Since then, the two teachers have continued this teaching method and made it grow and develop; eventually becoming what we call the "flip classroom" today.

\subsection{Flipping the concept of the classroom.}

Many scholars at home and abroad have defined the concept of flipping classrooms. However, there is no unified definition of concepts. By consulting a large amount of literature, it can be found that there are many interpretations at the macro level and the micro level [4]. At the macro level, "Flip the classroom" means "reversal of knowledge transfer and internalization of knowledge"; at the micro level, "flip classroom" refers to the use of modern educational technology and students to pass the network outside the classroom under the guidance of constructivism and mastery of learning theory. Self-study teachers pre-recorded teaching videos, in the classroom to highlight the 
teacher-student interaction and sharing, teachers provide students with personalized guidance of a teaching form. The flipping classroom mentioned in this article means that under the premise of having a network platform, the teacher can record the video to be taught in advance and provide the video to the students through the online platform. The students can watch the self before class, and adopt the appropriate one [5]. The learning method is to teach the technical movements that the teacher is about to teach. This application of multiple teaching methods organically links teachers, students and teaching videos to realize the internalization of extracurricular knowledge and the teaching of classroom knowledge and skills.

\subsection{Students are the protagonists.}

With the continuous advancement of science and technology, students have a variety of ways to acquire knowledge. They can complete the acquisition of knowledge according to their own needs through mobile phones, computers, etc. Therefore, flipping the classroom should use appropriate media to teach video or other Auxiliary tools, uploaded to the network and other platforms, students can learn anytime, anywhere, learning is no longer subject to the time of class and class, the place where you cannot learn can be repeated many times, but also can browse the knowledge at any time [6]. Peripheral information, to achieve knowledge, improves students' self-learning ability, planning ability and execution ability. In short, it is to make full use of the spare time to learn knowledge, and in the limited classroom time, with the help of the knowledge and teachers to complete the internalization and sublimation of knowledge, build a complete knowledge system. Therefore, flipping classroom students is the protagonist.

\subsection{Redistribute class time and improve efficiency.}

Flipping the classroom is to maximize the use of the classroom in practice. In the classroom, the teacher's explanation and demonstration time is greatly reduced, and the student's learning practice time accounts for the vast majority. In the process of physical education, the students' motor skills are consolidated through practice, which means that the acquisition of motor skills requires a lot of practice time [5]. This is also the reason why the physical education class has always advocated "speaking and practicing more". The traditional physical education classes are basically based on teachers' explanations and demonstrations. The time for students to practice is relatively small. If students want to get relevant sports skills effectively, they can only rely on spare time to practice, but this kind of extracurricular exercise is a random exercise without the guidance of the teacher [5]. Many motor skills may change greatly during the student's practice. When the students practice a certain number of times after class, the wrong motor skills are A fixed pattern will be formed in the minds of students, and it will be very difficult for teachers to correct them when they are in class. Turning the classroom is to let students have more practice time in the classroom, and teachers have more time to guide students. Therefore, flipping the classroom makes the exercises in class more efficient.

\section{Feasibility Analysis of Flip Classroom in Public Physical Education Teaching in Colleges and Universities}

4.1 Flipping the classroom can give full play to the teacher's leading role and the student's main role.

In the traditional public physical education, the teacher is always the main body of the classroom, the whole class, the teachers are constantly demonstrating, demanding and organizing, the students are always Passive participation in the public sports classroom, such public sports classroom teaching is inefficient, students are not very motivated, it is difficult to have a good teaching effect [6]. Flipping the classroom can change the status quo. Students can contact the teaching content in advance through the class, and ask questions from the teachers in the class to play the subjectivity of the students. 


\subsection{Flipping the classroom allows students to better master the public sports skills.}

According to the current stage of flipping the classroom teaching mode, the pre-class teaching form can generally be in the form of video or audio [3], students through the online course platform on the pre-class public Sports technology learns in advance, and through the study of video content, students can be more exposed to this technical action, student roots

\subsection{Flipping the classroom can better evaluate the students' teaching.}

Nowadays, the reform of public sports evaluation pays more and more attention to the process evaluation of teaching evaluation, that is, emphasizes the process evaluation, and cannot blindly adopt the summary evaluation. In the evaluation, the flipping class pays attention to the process evaluation of students, respects the process evaluation of students, and the learning attitude of students and classroom performance will become a large part of student evaluation [7]. For example, if a student's usual public sports skills are not so good, he can make more efforts under the class and constantly improve his public sports quality. Through his continuous efforts, he can improve his public sports skills and interests. This will not only achieve the meaning of evaluation, but also be more effective in promoting evaluation.

\subsection{Flipping the classroom can increase the training time of the students and better realize the teaching goal of health first.}

The flipping class emphasizes the students' under-school learning and emphasizes the autonomy of the students. This kind of teaching organization can make the students unconsciously under the class, take more time to carry out physical exercises, and the time spent by the students will greatly reduce the time for teachers to explain in the classroom [7]. This will also increase the time for students to practice in class, and the growth of students' practice time will continue. Improve your physical fitness and skills to better achieve the "health first" teaching goals.

\section{Research on the application of flipping classroom in public physical education in colleges and universities}

The traditional teaching mode is the leader of the high-level teaching. During the whole process, the teacher teaches in one direction, and there is no communication between the teachers and students. How much knowledge the students have and what problems they encounter, the teachers cannot get timely feedback. Informatization today, it has become a habit for students to use mobile phones and computers for learning and communication [6]. Teaching informationization is an inevitable trend of teaching reform. The flipping classroom teaching mode is adapting to students' learning habits and narrowing the gap between teachers and students. The distance has created a multi-disciplinary and interactive communication mechanism between teachers and students, which eliminates the concept of teacher-student level and the equality between teachers and students, which is conducive to the formation of a good sports learning atmosphere.

\subsection{The construction stage of the pre-class teaching platform.}

The main meaning of flipping the classroom is to subvert the meaning between the pre-class and the class, and put the relevant teaching content before the class for the students to study, so the construction of the pre-school teaching platform is very important. The construction of this teaching platform should be divided into the following three contents [7]: Firstly, some technical decomposition video and training videos or courseware of public sports are uploaded into the teaching platform to enrich the resources of the teaching platform; secondly, the teaching platform should be utilized. Students conduct teaching evaluations, such as the usual click-through rate of students, the number of times users log in, the time of viewing content, etc., and use these historical records to achieve procedural evaluation of students, in order to increase the consciousness of students' learning. Third, the teaching platform of this course should include the communication process between the students and the teachers. Students can not only communicate with the teachers in the class during the ordinary study, but also communicate with the teachers in normal times, and 
can realize the communication between the teachers and the students for 24 hours.

\subsection{Students in the class will improve the public sports related skills and theory.}

The teaching classroom of flipping classroom is very different from the traditional public physical education classroom. The traditional public physical education classroom is basically controlled by one teacher, and the participation of students is very passive. Such a public physical education classroom loses the true education. Meaning lost the subjectivity of students' learning [8]. The flipping of the classroom teaching form has changed the current situation of the traditional public physical education. The students visualized the teaching content before the class, and communicated with the teacher with questions and questions during class. This makes the teaching have a great directionality. The teachers in the class organize and analyze the questions according to the students' questions, organize the teaching according to the students' problems, and can also carry out targeted group teaching according to the students' problems. Solve the problem autonomously.

\subsection{Post-class evaluation and self-improvement stage.}

The teaching evaluation of flipping classroom is more emphasis on process and difference evaluation. The evaluation method runs through the whole semester process. Students learn public sports skills because of their physical quality. Differences are made in different ways, so there will be some situations where the usual hard work, but the final learning results are not very satisfactory [8]. Because of the construction of its teaching platform, the flipping classroom makes the students' ordinary efforts and learning attitudes well reflected, and it is easier to evaluate the students' learning attitudes, which respects the students and makes the teaching evaluation reach its due "Promoting learning by evaluation." Moreover, due to the construction of its teaching platform, the opportunities for students and teachers to communicate are increased [8]. Communication and feedback between teachers and students, feedback and feedback, constantly solve problems in teaching and learning, form dynamic development of teaching tasks and goals, and continuously consolidate and improve.

\section{Summary}

Flipping the classroom is a very important form of teaching in the information age. This form of teaching changes the existing traditional teaching concepts. The novel teaching organization will enable students to better participate in the classroom and learning, better It is very necessary to carry out this teaching method in public physical education classes and even physical education classes in colleges and universities by giving full play to the subjectivity of students' learning. Through the teaching design of three teaching hours before class, during class and after class, the practice of flipping classroom in public physical education is realized; this is the basis for the promotion of flip teaching.

\section{References}

[1] G.L. Wang, Research on the value and implementation strategy of introducing physical education into the classroom, Journal of Beijing Sport University, 2016, vol.2, pp.105-107.

[2] H.J. Liu, Research on the Construction of College Physical Education Teaching Model Based on "Flipping Classroom", Sichuan Sports Science, 2015, vol.5, pp.13-14.

[3] B.L. Cai andY.Y. Ma, Feasibility Analysis of the Application of Flipping Classroom Teaching Model in Chinese Colleges and Universities, Software Guide, 2013, vol.7, pp.7-11.

[4] H.J. Zhu, Flipping classroom and its effective implementation strategy, Research on Electrochemical Education, 2013, vol.8, pp.79-83.

[5] X.L. Zhong and L.Zh. Li, Teaching Design Research Based on the Concept of Flipping Classroom in Information Environment, Open Education Research, 2013, vol.1, pp.58-61.

[6] Ch.J. Wang and W.P. Hu, "Flip classroom” technology to promote teaching, Research on 
electrification education, 2013, vol.8, pp.73-75.

[7] X.F. Chen, Research on flipping classroom teaching mode, Huazhong Normal University, 2014, vol.2, pp.88-90.

[8] W.T. Xu and Sh.Ch. Zhong, Research on Chemistry Experiment Teaching Model and Support System Based on Flip Class, Journal of Distance Education, 2013, vol.5, pp.107-112. 